\title{
Contribuições teóricas dos estudos de performance para a análise da dinâmica das relações entre turismo e cultura
}

\section{Theoretical Contributions of the performance studies to analyze the dynamics of the relationship between tourism and culture}

\author{
Karoliny Diniz Carvalho (CARVALHO, K. D.) ${ }^{*}$
}

\begin{abstract}
RESUMO - O artigo busca analisar as contribuições da teoria da performance para a análise da dinâmica das relações entre turismo e cultura, notadamente no que se refere ao processo de transformação das manifestações populares em produtos de lazer e entretenimento. Discute as novas possibilidades de interpretação dos eventos turísticos para além das categorias de aculturação e autenticidade, enfatizando a reflexividade e a tradução cultural visando o entendimento das modificações dos conteúdos simbólicos dos sistemas culturais a partir das quais se afirma uma determinada representação identitária como forma de legitimação da experiência turística.
\end{abstract}

Palavras-chave: Turismo; Performance; Formas Festivas; Identidade; Tradução Cultural.

ABSTRACT - The article reviews the contributions of the performance theory to analyze the dynamics of the relationship between tourism and culture, especially in relation to the transformation process of the popular manifestations in entertainment and leisure products. It discusses the new possibilities of touristic events interpretation in addition to the categories of acculturation and authenticity, emphasizing reflexivity and cultural translation in order to understand the modifications of the cultural systems symbolic contents from which state a particular identity representation as a way of legitimizing the tourist experience.

Key words: Tourism; Performance; Celebrations; Identity; Cultural Translation.

\footnotetext{
* Graduação em Turismo pela Universidade Federal do Maranhão (UFMA). Mestrado em Cultura e Turismo pela Universidade Estadual de Santa Cruz (UESC), Ilhéus, Bahia (BA). Doutoranda em Ciências Sociais pela Universidade Federal do Maranhão (UFMA). Bolsista da Coordenação de Aperfeiçoamento de Pessoal de Nível Superior (Capes). Endereço Postal: Rua Barão do Rio Branco, Quadra I, número 14, Sítio Leal. CEP: 65045-340 - São Luís - Maranhão (Brasil). E-mail: karol27_turismo@yahoo.com.br
} 


\section{INTRODUÇÃO}

O turismo enquanto fenômeno social vem contribuindo para o revigoramento ou restauração das culturas, por intermédio da formatação de produtos, eventos e atrações, nas quais os visitantes possuem a oportunidade de vivenciar aspectos da cultura local, resultando assim, no retorno sócioeconômico para as comunidades.

Diante da intensificação dos processos culturais, do descentramento identitário e da comercialização de signos, imagens e representações no mercado de consumo, as práticas sociais são revisitadas e reelaboram seus significados, estabelecendo novas formas de expressão das identidades.

No contexto turístico, os sistemas simbólicos são utilizados como fatores catalisadores de fluxos de visitantes e, conseqüentemente, tendem a gerar oportunidades de dinamização econômica para diversas localidades. Ao atraírem um público consumidor específico, as festas populares tradicionais - sagradas ou profanas inserem-se no jogo dialético e dinâmico de seleções e negociações de seus elementos definidores, a fim de se conformarem em produtos de lazer e entretenimento.

A redefinição das práticas culturais pela atividade turística suscita questões referentes à autenticidade dos eventos, festas e celebrações, bem como à espetacularização e a ressemantização dos seus significados, considerando o processo de fragmentação ou dissolução das identidades globais. Emerge, assim, a necessidade de compreender as mudanças nas práticas culturais enquanto resultado das diferentes formas de manifestação dos aspectos simbólicos experienciados pelos grupos sociais na sua vivência cotidiana e festiva.

Tais momentos podem ser entendidos como unidades de ação ou sequência de eventos, e permitem a mobilização e o acionamento de diferentes identidades em contextos distintos. Nos lugares institucionalizados, a diferença é vista como elemento de atração turística; ao interpretarem as memórias e identidades locais sob a forma de atrações estilizadas para grupos de turistas e visitantes, os grupos sociais transformam as festas em estruturas polifônicas, nas quais se verificam mecanismos de seleção e ativação de múltiplas identidades. Tais identidades são passíveis de se articularem, ou seja, de serem manipuladas e representadas de forma situacional e estratégica. 
Assim, a apreensão dos significados das festas comunitárias só se torna possível inserindo-as no âmbito das ações performadas, isto é, quando as memórias e identidades estão em situação de performance ${ }^{l}$ cultural. Implica, portanto, numa visão interpretativa das estruturas simbólicas (GEERTZ, 1989) que são encenadas ou representadas enquanto "texto” para um público específico, numa perspectiva dialógica e relacional.

O objetivo deste trabalho consiste em estabelecer uma aproximação entre as proposições teóricas dos estudos de performance e as investigações no âmbito da relação turismo/cultura, notadamente no que se refere ao processo de transformação das manifestações populares em produtos de lazer e entretenimento. Mediante uma abordagem interpretativa da cultura, realizou-se pesquisa bibliográfica e exploratória. Procedeu-se às etapas de levantamento, sistematização e análise de dados disponibilizados na literatura científica nas áreas de turismo e antropologia da performance, visando à elaboração de um marco teórico-conceitual acerca do tema proposto.

A argumentação desenvolve-se a partir de conceitos e noções sobre identidade (TEJERINA, 2003; CARDOSO DE OLIVEIRA, 2006), performance (SINGER, 1972; TURNER, 1982), reflexividade (SCHECHNER, 2003) e tradução cultural (BHABHA, 1998), no sentido de problematizar as transformações nos conteúdos semânticos das manifestações festivas enquanto atrativos turísticos.

Preliminarmente, expõem-se as relações entre formas festivas, turismo e processos de hibridação no contexto da globalização do capital econômico e simbólico, reconhecendo a função desempenhada pelo turismo na ativação de processos identitários. Em seguida, o artigo aborda a aplicabilidade de alguns conceitos, temas e abordagens relativos às teorias da performance no turismo, com o fito de contribuir para a formulação de novas questões e problemáticas inerentes à relação entre turismo e sistemas simbólicos.

As reflexões propostas operam em torno de duas questões complementares: por um lado, o entendimento de que o turismo produz reativações identitárias sob a forma de produtos para o consumo, estabelecendo novas formas de sociabilidade; e de outro, a perspectiva de que as formas culturais agenciadas pela atividade turística constituem zonas fronteiriças de tradução cultural, espaços liminares nos quais se entrelaçam o

\footnotetext{
${ }^{1} \mathrm{O}$ termo performance deriva do francês antigo parfournir , significando "completar" ou "realizar inteiramente", ou seja, diz respeito ao momento de expressão, de completar uma experiência.
} 
ritual e o espetáculo, observando-se elementos de continuidade e descontinuidade, reforço, reiteração e transformação.

\section{FORMAS FESTIVAS, TURISMO E PROCESSOS DE HIBRIDAÇÃO}

Compreende-se por festas ou formas festivas o conjunto de eventos públicos, tais como o carnaval, as paradas, concertos, feiras, quermesses, funerais, festas de santos, procissões, competições esportivas, comemorações cívicas e demonstrações política, julgamentos, a partir dos quais as diferentes formações identitárias são gestadas, vividas, compartilhadas e imaginadas por seus membros (GUSS, 2000).

Tratam-se de momentos de comemoração e congraçamento popular que possuem o seu enraizamento e organização no interior de uma determinada comunidade, sendo importantes no processo de coesão social e de reforço da memória e dos valores identitários de um lugar. As festas e celebrações populares caracterizam-se como bens simbólicos, estando associadas à vivência coletiva e às criações e recriações comunitárias, e consideradas expressões da fé, louvor, criatividade e inventividade que particularizam determinado grupo e região:

[...] as festas, rituais e celebrações, as formas de expressão diferenciadas, os modos de fazer enraizados no cotidiano das comunidades, os lugares onde se concentram e reproduzem práticas coletivas são práticas culturais que se tornaram passíveis de se tornar patrimônio, i.e., de se atribuir valor e significados que amalgamam grupos (CHUVA, 2002, p. 156).

Acrescidas a elas advém uma rede de relações sociais e códigos culturais presentes nos símbolos, na divisão do trabalho entre os gêneros, nos cânticos, na gastronomia, na musicalidade, os quais conferem sentido e significado às formas sociais e simbólicas pelas quais os grupos agem, interagem e afirmam-se enquanto diferença e singularidade perante os seus semelhantes e os outros.

A partir do conceito de liminaridade cunhado por Tuner (1974), compreende-se que as manifestações festivas irrompem as estruturas cotidianas, sugerindo um momento especial de prazer coletivo. Estão inseridas no vasto universo do teatro, do jogo e do ritual, e envolvem de forma complementar e simultânea troca de favores e obrigações, divertimento, compromisso, lazer e entretenimento. 
Guarinello (2001) entende a festa como realidade integrada ao cotidiano, caracterizando-a como produto de uma ação coletiva que ocorre em espaço e tempos definidos, mediante a articulação de afetos e emoções dos grupos em torno de um objeto que é celebrado e comemorado. Sua reunião produz como resultado principal a simbolização de uma unidade entre os seus participantes. Para o autor, a festa é ao mesmo tempo produto de determinadas relações sociais - bem como dos conflitos e contradições nelas existentes - e produtora de diversas memórias e identidades que amalgamam grupos.

Constata-se que nas formas festivas as identidades estão em constante trânsito, movimento ou circulação, assumindo, portanto, um caráter provisório. Na visão de Cardoso de Oliveira (2006), as discussões em torno do tema identidade permitem compreender que esta se apresenta pluralizada e dinâmica. Isto significa que há uma identidade - que pode ser central em alguns momentos - mas que está em constante contato com outras identidades possíveis, podendo incorporar ou rejeitar elementos de outras identidades.

Por meio de processos relacionais de apropriação, seleção e negociação, são ativadas ou acionadas determinadas formas identitárias, as quais congregam grupos específicos em torno de questões como identificação, distinção e reconhecimento. Esses elementos confluem e constituem o que denominamos identidade coletiva, ou seja:

\footnotetext{
[...] um sentimento de pertença partilhado pelos membros de um grupo ou por vários grupos, mediante o qual a realidade é definida e interpretada, orientando as acções dos que dele participam. A identidade colectiva pode cristalizar e objectivar-se, porém está sujeita a todo o momento à possibilidade de mudança e reelaboração (TEJERINA, 2003, p. 24-25).
}

A identificação pressupõe a diluição de fronteiras entre as identidades, a existência de pontos de interstícios e de deslocamento entre os diferentes sistemas culturais. Assim, os indivíduos estabelecem determinados elementos que são apreendidos como traços distintivos de sua cultura, os quais se tornam alicerces para a construção das identidades. Na contemporaneidade, as identidades tornam-se cada vez mais compartilhadas, sofrendo constantes processos de hibridismo cultural, o que resulta na formação de indivíduos traduzidos, os quais assumem diferentes posições ou referências identitárias (CANCLINI, 2000). 
O imaginário, os valores simbólicos, as relações identitárias, a vivência cotidiana e festiva dos grupos sociais apresentam-se como importantes recursos ou atrativos turísticos. O turismo cultural baseia-se na produção material e espiritual de uma comunidade, ou seja, transita em torno dos patrimônios culturais que são apropriados e recriados na dinâmica social, transformado-os sob a forma de roteiros, produtos e atrações.

Na visão de Lucas (2000), o turismo pode ser apreendido como a combinação das manifestações autênticas de um determinado local, município ou região, atrelado à existência de serviços e infraestrutura para sua apresentação, promovida por moradores, profissionais ou administradores. $\mathrm{O}$ contato intercultural proporcionado pelo turismo tende a contribuir para o fortalecimento do sentido de pertencimento dos atores sociais em relação à sua cultura, mediante a compreensão do seu lugar social e cultural, e favorecendo perspectivas de valorização e revitalização do patrimônio cultural.

Considerando-se que o turismo abrange um conjunto de elementos interdependentes, bem como uma diversidade de relações, enfatiza-se a sua categorização no âmbito dos chamados fenômenos sociais totais, conforme terminologia proposta por Mauss (1974, p. 41), na medida em que estes:

[...] exprimem-se, ao mesmo tempo e de uma só vez, toda espécie de instituições: religiosas, jurídicas e morais - estas políticas e familiais, ao mesmo tempo; econômicas — supondo formas particulares de produção e consumo, ou antes, de prestação e de distribuição, sem contar os fenômenos estéticos nos quais desembocam tais fatos e os fenômenos morfológicos que manifestam essas instituições.

Enquanto fenômeno social total oportuniza o intercâmbio entre culturas ao possibilitar o convívio dos turistas com os aspectos representativos do patrimônio cultural local. Com base nos estudos antropológicos sobre o turismo, Burns (2002) observa que a atividade é entendida por alguns autores como um ritual ou peregrinação pós-moderna, uma vez que implica estados de transitoriedade e mudança dos visitantes durante e após a sua experiência num determinado lugar.

Nesse sentido, enquanto prática de lazer, o turismo representa um período particular de ruptura do cotidiano, assemelhando-se aos elementos que compõem os ritos de passagem analisados por Van Gennep (1978) - separação, liminaridade e incorporação. Durante as viagens turísticas, observa-se a liberação dos comportamentos 
em virtude do relaxamento ou suspensão das regras e normas de convívio social; a passagem ou transposição de status dos visitantes após a experiência turística e, em alguns casos, a inversão ou a afirmação dos valores e imaginários pré-concebidos durante o planejamento da viagem. Ao regressarem, os turistas são reincorporados à sua sociedade de origem. Assim, o turismo sempre implica um processo de transformação ou mudança social.

$\mathrm{Na}$ contemporaneidade, o modo de produção capitalista modificou-se, assumindo novas diretrizes, ao mesmo tempo em que estende seus raios de influência pelas diversas regiões. Empresas transnacionais e supranacionais engendram novos mecanismos de produção, comercialização e distribuição de bens e serviços no mercado mundial.

$\mathrm{O}$ surgimento de redes globais que se entrelaçam e atuam em diversos setores da sociedade, tais como o econômico, o de artes e comunicação, o de entretenimento e lazer, promovem alterações nas relações interpessoais; estas passam a se caracterizar, cada vez mais, pela fragmentação do espaço-tempo, conforme explicita Giddens (2002). No nível cultural, estas mudanças refletem num movimento contínuo de ressignificação das práticas sócioculturais tradicionalmente estabelecidas, as quais se adéquam às especificidades e necessidades presentes no interior de cada realidade social.

Nesse cenário, o turista pós-moderno personifica a figura do peregrino, deslocando-se no sentido de vivenciar experiências autênticas que promovam situações de educação, aprendizado e reciprocidade cultural. Ao mesmo tempo em que aproxima e promove a interação entre os grupos sociais, a globalização produz alterações na configuração territorial. Os lugares e as práticas culturais são constantemente reproduzidos por uma nova dinâmica, sendo a atividade turística um dos elementos suscitadores desse processo.

O turismo insere-se no jogo de alteridades, injunção e disjunção, encontro e confronto com a diferença cultural que se faz presente nos sistemas simbólicos dos atores sociais envolvidos - visitantes e cicerones - refletindo uma relação dialógica e intersticial, na medida em que sobrepõe o ordinário e o extraordinário, o cotidiano e o extracotidiano.

Face à complexidade do fenômeno turístico, torna-se explícita a sua faculdade de transpor os limites e as fronteiras locais, regionais e nacionais, estendendo a sua área 
de influência para todas as esferas da sociedade globalizada, num mecanismo que intensifica as relações de produção, distribuição e consumo de bens tangíveis e intangíveis, com repercussões na vida social, política, ambiental, econômica e cultural do lugar visitado.

A aceleração do intercâmbio cultural, atrelada às modernas tecnologias da informação e da comunicação, ocasiona o surgimento de produtos culturais híbridos, que transitam em diferentes sistemas culturais e não possuem fronteiras definidas, desconstruindo, assim, a concepção tradicional do termo cultura. Em articulação aos processos de produção e circulação de bens simbólicos, as festas populares passam a adotar novas funções e significados, associadas ao desenvolvimento de atividades de ócio e de lazer e em virtude da presença de visitantes.

A incorporação das culturas no circuito turístico provoca mudanças nas atitudes dos viventes em relação ao seu cotidiano e às praticas culturais ditas tradicionais; estas passam a obedecer às novas racionalidades e funções atreladas à importância dos signos e do espetáculo para o turismo, "devido a sua particular combinação do visual, do estético e do popular" (URRY, 1996, p. 123).

O redimensionamento dos fatos culturais para a notoriedade turística resulta, em alguns casos, na perda da continuidade cultural, em face da sublevação do aspecto mercantil ao aspecto identitário. Em determinados destinos turísticos, as festas e danças populares são ressignificadas, ocasionando a banalização das festas tradicionais, e a transformação de rituais sagrados em rituais de entretenimento (SANTANA, 2009).

Nesse sentido, Carvalho (2000, p. 79) adverte que os rituais sofrem uma redução semiológica e semântica a partir do momento em que se configuram como um espetáculo comercial. Segundo o autor, este tende a desvincular das manifestações "suas dimensões locais de identidade, pertença, religiosidade, consciência histórica, criação estética, originalidade, fonte de auto-estima e resistência política."

Mediante essa proposição, o turismo insere-se num amplo processo de regeneração das culturas e das identidades locais, enquanto estratégia de inserção econômica e de diferenciação no mercado, dando origem a novos contornos e matizes às manifestações festivas. Para além da aculturação, compreende-se atualmente que os sistemas culturais postos em contato incorporam determinados elementos, promovendo 
constantes reinterpretações e ressignificações culturais, sendo os grupos sociais agentes criativos da mudança e da inovação.

No entendimento da dinâmica dos processos culturais, torna-se importante enfatizar a perspectiva de Turner (2008), para quem os símbolos expressam a diversidade da ação simbólica humana, sendo entidades flexíveis, polissêmicas e multivocais. Apresentam uma abertura semântica mediante a polarização de seus significados, os quais variam de acordo com o contexto ritual onde estão inseridos. Assim, as configurações de uma determinada cultura só podem ser entendidas considerando-se a arbitrariedade e a gerência dos atores sociais, assim como a relação entre os símbolos e a estrutura mais ampla que lhe confere significado.

Considerando que as festas e celebrações populares referem-se a momentos diferenciadores da vida cotidiana atraindo um público consumidor específico - os turistas - torna-se necessário compreender as interações que se estabelecem quando os bens simbólicos inserem-se no mercado turístico global, dando origem a produções culturais dinâmicas, híbridas, móveis e polissêmicas e, por isso, sendo constantemente reelaboradas pelos grupos sociais.

No universo das modificações da cultura, aos significados simbólicos e ritualísticos inerentes a uma determinada forma festiva - que pode ser uma brincadeira popular, uma cerimônia, uma celebração profana ou religiosa - incorporam-se os valores de fruição estética e ludicidade típica dos jogos teatrais.

Essas dimensões alinham-se com a caracterização de performances culturais objetadas por Singer (1972), as quais podem ser entendidas como formas de expressão artística e cultural que obedecem a uma programação prévia da comunidade, com uma seqüência determinada de atividades, local próprio para sua ocorrência, horário definido de início e fim, delimitação entre performers e público. Assim, pode-se incorporar às festividades populares o conceito de performance. Nelas imbricam-se cinco dimensões chaves:

First, cultural performances are temporally and spatially framed. Second, they are programmed, following a more or less structured order of activities. Third, cultural performances are communal insofar as they provide an occasion for coming together. Fourth, cultural performances are heightened occasions involving display. Fifth, cultural performances tend to be prepared for and often publicized in advance (FOUSS e HILL, 2000, p. 111). 
Partindo-se do princípio de que as identidades são realidades performatizadas, conforme aponta Guss (2000), uma manifestação de caráter religioso, artístico ou cultural pode ser apreendida como performance, no sentido em que ela expressa tanto para os grupos que a legitimam como para os espectadores, determinadas formas identitárias que estão inseridas numa matriz diversificada de referências pela qual os grupos sociais estão constantemente sendo submetidos.

Turner (1982, p. 11) apresenta uma definição ampla e polissêmica sobre o conceito de performance, tendo em vista sua multidimensionalidade, na qual se imbricam feições estéticas, interculturais, históricas e atemporais, sociológicas e políticas, "Performance é um modo de comportamento, um tipo de abordagem à experiência humana; performance é o exercício lúdico, esporte, estética, entretenimento popular, teatro experimental e muito mais."

Schechner (2003, p. 27) percebe a existência de um continuum indissociável entre a performance e a vida cotidiana, compreendendo as performances como ações coletivas que se caracterizam como comportamentos duplamente exercidos, ações performadas e comportamentos restaurados que são incorporados e desempenhados pelos atores sociais em sua vivência cotidiana e na sua interação com os demais membros de uma sociedade:

[...] Performances afirmam identidades, curvam o tempo, remodelam e adornam corpos, contam histórias. Performances artísticas, rituais ou cotidinas - são todas feitas de comportamentos duplamente exercidos, comportamentos restaurados, ações performadas que as pessoas treinam para desempenhar . [...] A vida cotidiana também envolve anos de treinamento e aprendizado de parcelas específicas de comportamento, e requer a descoberta de como ajustar e exercer as ações de uma vida em relação as circunstancias pessoais e comunitárias.

Nesse sentido, tradição e modernidade, essencialidade e artificialidade, espetáculo e encenação, são elementos que coexistem em diferentes sistemas culturais e se adéquam às maneiras de agir dos grupos no corpus social. As formas festivas prescindem das estratégias de restauração para a fixação de comportamentos, ao tempo em que se utilizam da ação teatral no sentido de validar a representação desejada em uma realidade específica.

Nas performances culturais, ocorrem mecanismos de identificação e apropriação de elementos, técnicas, materiais e formas culturais emergentes, caracterizando uma 
tradução e atualização das culturas, ou um processo de enraizamento e reenraizamento. Recorre-se à noção de tradução na busca pelo entendimento de que o hibridismo cultural surge como um processo de releitura e de incorporação de novos elementos. Consiste, portanto, em "viver nas fronteiras", estar num "entre-lugar"; é ainda, "uma condição de hibridismo que confere poder, uma emergência que transforma o retorno em reinscrição" (BHABHA, 1998, p. 311).

Nesse particular, as teorias da performance e da representação teatral tornam-se úteis ao possibilitarem uma reflexão sobre as relações sociais, ao tempo em que aprofundam o debate em torno dos significados dos eventos, lugares turísticos e das produções culturais que caracterizam os fluxos inter e transculturais contemporâneos. Neles, transposição, repetição, inovação e criatividade são características que se fazem presentes no processo de restauração cultural.

\section{A TEORIA DA PERFORMANCE APLICADA AOS ESTUDOS DE TURISMO E CULTURA}

Nas últimas décadas, têm-se intensificado os estudos sobre as formas festivas e os processos de hibridação nas sociedades, sobretudo, sua interface com o turismo, na medida em que a experiência cultural em suas múltiplas dimensões - social, estética, ritualística, simbólica - é ressignificada e formatada como produto turístico dotado de valor econômico no mercado de consumo. Essas investigações inserem-se no contexto da antropologia da performance, tendo como expoentes Turner (2008), Shechner (2003), Dawsey (2005) e Langdon (2007).

A performance tem sido teorizada por diversos autores como um meio através do qual os grupos atuam e interagem em sociedade, organizando suas formas de experienciar o mundo social. Constitui um conceito central para a visão contemporânea de cultura enquanto construção simbólica incorporada, reivindicada, representada e comunicada por meio de práticas sociais diversas que são desempenhadas pelos atores sociais ao longo da sua vida cotidiana (GOFFMANN, 1995).

Na presente abordagem a ênfase é dada aos aspectos emergentes, temporários e negociáveis dos eventos ou das produções culturais, privilegiando um olhar 
construtivista que revela não somente os seus conteúdos semânticos, mas, sobretudo, a sua historicidade, as descontinuidades, a ingerência dos grupos sociais, os elementos liminares. Conforme expõe Ligiéro (2003, p. 90) "o estudo da performance combina antropologia, artes performáticas e estudos culturais, usando lentes inter-disciplinares para examinar um conjunto de atos sociais: rituais, festivais, teatro, dança, esporte e outros eventos ao vivo".

As teorias da performance tornam-se fundamentais para se compreender as diferentes formas de configuração das manifestações festivas quando inseridas no contexto de trocas interculturais e constantes influências externas, resultando na incorporação de linguagens, estilos e técnicas que denotam novos valores e significados às formas e conteúdos materiais e simbólicos das expressões populares.

Ao analisar as diversas abordagens de performance presentes na literatura antropológica, Langdon (2007) arregimenta e sintetiza cinco qualidades que demonstram as suas potencialidades como paradigma conceitual interdisciplinar importante para a compreensão das diferentes formas de ação simbólica presentes nas sociedades contemporâneas: 1) Experiência em relevo, na medida em que a performance é entendida como uma experiência pública, momentânea e espontânea, um comportamento realçado, intensificado; 2) Participação/ Expectativa, a qual se refere à participação plena de todos os presentes para criar a experiência: o ator (performer), a forma artística, a platéia, e o contexto, cujas interações fazem emergir a poética, o significado e o sentido do evento; 3) Experiência multissetorial, que envolve diversas combinações de ritmos, luzes, cheiros, música e movimento corporal; 4) Engajamento corporal, sensorial e emocional, enfatizado a subjetividade dos participantes da performance e 5) Significado emergente, entendendo a performance como processo no qual os valores, os significados e as práticas sociais e culturais estão sendo permanentemente criados.

As ações performáticas estão presentes nas esferas de lazer e do consumo nas sociedades contemporâneas, sendo entendidas por Turner (1982, p. 4) como fenômenos liminóides, por serem fragmentárias, experimentais, destituídas da obrigatoriedade típica dos rituais, "mas caracterizam-se como atividades de adesão voluntária, optativa e individual". No contexto turístico, o conjunto de experiências e a atmosfera que as envolve situam-nas entre o ritual e o espetáculo, o sagrado e o profano, entre a diversão 
e a devoção, mediadas pelas empresas turísticas, órgãos oficiais de turismo ou pela iniciativa privada.

Para Schechner (2003) a performance compreende um movimento contínuo que vai do "rito" ao "teatro" e vice-versa. Detendo-se na relação entre performer e audiência, o autor associa ao ritual a característica de eficácia simbólica e ao teatro a função de entretenimento. No entanto, aponta para a existência de uma relação intrínseca entre eles, uma vez que essas duas categorias representam eventos de uma mesma natureza. Dessa forma, Schechner (2003) enfatiza a importância do contexto, da função, das condições que propiciaram sua realização perante determinado público, a fim de caracterizá-la enquanto performance.

Dessa forma, o teatro e o ritual não são vistos como campos separados, o que permite considerá-los locais de intersecção ou de fronteira. As características presentes em cada um desses campos (TABELA 1) diluem-se, permeiam-se, transformando o evento turístico num produto híbrido, multifacetado e, portanto, dinâmico.

\section{TABELA 1 - ELEMENTOS CONSTITUINTES NO UNIVERSO DO TEATRO E DO RITUAL}

\begin{tabular}{l|l}
\hline EFICÁCIA (RITUAL) & ENTRETENIMENTO (TEATRO) \\
\hline Resultados & Divertimento \\
Ligação com o outro ausente & Somente para os que estão lá \\
Tempo simbólico & Énfase no agora \\
Performer possuído, em transe & Performer sabe o que está fazendo \\
Plateia participa & Plateia aprecia \\
Criticismo é desencorajado & Criticismo floresce \\
Criatividade coletiva & Criatividade individual \\
\hline
\end{tabular}

FONTE: Ligiéro (2007)

As formas festivas constituem-se, assim, espetáculos estilizados e midiáticos, nos quais os diferentes atores interagem dentro de um contexto e função específicos, estabelecendo novos vínculos em relação à ação performada. A performance turística envolve não apenas a linguagem corporal dos performers, mas a musicalidade, a cenografia, a ambiência, o espetáculo de luzes que geram uma atmosfera propícia para as interações turísticas. O principal objetivo, sua eficácia simbólica, reside em maximizar o potencial de satisfação da experiência turística.

Nesse contexto, os atores sociais desempenham determinadas funções e papéis, performam ações para um determinado público de espectadores, os quais também auxiliam no processo de configuração da festa como constructo social. A noção de 
performance na análise da relação da dinâmica entre o turismo e a cultura pressupõe que as identidades comunitárias estão em circularidade, trânsito, num constante saberfazer que irrompe a distância espaço-temporal, permitindo o entrecruzamento de diferentes vozes, temporalidades, e discursos que estão dispostos no jogo de relações, confrontos, negociações e resistências.

As formas festivas não fazem parte de sistemas simbólicos isolados, uma vez que permitem adaptações, variações, a partir do contato com diferentes grupos sociais, dando origem a novas produções culturais para fins de adequação ao calendário turístico. As recriações de festas e brincadeiras populares pressupõem sempre uma reconfiguração, uma mudança semântica que se adéqua à lógica do sistema cultural que a opera.

Os performers extraem da sua realidade cotidiana os elementos que produzem a encenação - ritual, artística e turística - ou tomam de empréstimo de outros sistemas culturais informações, elementos e tecnologias, transformando a performance numa estrutura complexa, extensão de sua vivência individual ou subjetiva. Tomando-se por base as reflexões de Canclini (2000) observa-se a superposição de elementos oriundos de diferentes tradições, etnias, nações, com o consequente esfacelamento da polarização até então existente entre o tradicional e o moderno, o erudito e o popular.

Assim, no âmbito das manifestações de trabalho e lazer, festa e devoção, ritual e espetáculo, sobressaem-se diferentes performances, performers e espectadores, os quais conferem sentidos e significados à representação de acordo com variados interesses e expectativas. É essencial o entendimento de que as estruturas que integram as performances culturais são dinâmicas, processuais e situacionais.

Seja na interação entre os performers e os espectadores, no desempenho de funções e papéis sociais, seja na perspectiva relacional com os visitantes, os atores sociais acionam e revisitam suas identidades através das manifestações festivas, agora reincorporadas na dinâmica social, numa releitura de seus elementos definidores. Possibilitam, assim, arranjos diferenciados quando da sua vinculação como elemento de reatualização das memórias comunitárias, de efervescência popular ou como bem de consumo turístico:

Na performance pública, a identidade é diretamente posta à prova da representação, forma-se e transforma-se sob o olhar do outro. Ela não é mais, naquele momento uma identidade que se afirma, que se define ou que é protegida, como se fosse uma realidade em si, um objeto sem sujeitos. 
Assumir o risco de exibir, de encenar os atributos culturais que pensamos como próprios, específicos de uma identidade ante os outros, é tornar essa identidade mais aberta, mais dinâmica e finalmente mais real por ser melhor apropriada na comunicação da performance (AGIER, 2003, p.60)

Bruner (2004), em sua análise sobre a performance da vida e cultura de jovens guerreiros da tribo Massai no Rancho Mayer - propriedade privada de remanescentes de uma família britânica localizada no leste da África - assinala que ocorre um processo de construção idealizada de um drama colonial num espaço e tempo pré-determinados.

Segundo o autor, a recriação do universo simbólico presente na vila Massai configura um lugar turístico liminar ou de fronteira e, portanto, um teatro de experiência. Neste, as tradições Massai são revisitadas e, em alguns casos, adaptadas, inserindo-se num jogo de interesses no qual se sobressai a manutenção da tribo frente às novas demandas políticas, sociais e culturais, das quais a atividade turística constitui-se parte integrante.

Mediante a pesquisa etnográfica, as danças, cantos, e rituais que envolvem a transposição de status dos jovens guerreiros na cultura Massai produzem um efeito realista nos visitantes que se completa com a tradição do chá inglês no jardim do Rancho Mayer, reforçando, assim, a oposição entre a resistência tribal e o colonialismo. As apresentações realizadas atrelam-se ainda à necessidade de confirmar as expectativas de retorno nostálgico à vida selvagem e exótica da África colonial presentes no imaginário dos visitantes.

Paralelamente, torna-se um palco revelador das negociações, diferenças, conflitos e paradoxos existentes entre a realidade social e cultural dos Massai e a representação de sua narrativa identitária que é encenada enquanto performance turística.

Por seu turno, Grünewald (2009) assinala as novas produções de sentido nos territórios ou arenas onde se processam as interações turísticas, tendo como foco de interesse o revigoramento da cultura pelos índios pataxó localizados na reserva da Jaqueira, Porto Seguro, Bahia. No âmbito da renovação cultural, vem ocorrendo um aumento da visibilidade desses grupos no mercado globalizado, por meio da comercialização de peças artesanais, realização de apresentações culturais, e das visitas sistemáticas de grupos de visitantes no aldeamento indígena. 
Nesse patamar, o turismo tem contribuído para a dinamização da economia local e para a restauração de uma etnicidade específica, baseado nas premissas do etnodesenvolvimento:

[...] embora ainda se questionem as formas de apresentações turísticas em relação à sua autenticidade ou à suposta transposição desta para outro contexto que não o original, são justamente as emergências e processos sociais e simbólicos dessas arenas turísticas que merecem exame como espaços sociais criados por demanda que motivas o nativo a 'reconstruir' sua etnicidade e renovar sua cultura de referência (GRÜNEWALD, 2009, p.113114).

Uma das perspectivas centrais dos estudos de performance apontada por Schechener (2003) relaciona-se à reflexividade, mecanismo que permite aos participantes de uma determinada performance refletirem sobre si mesmos, sobre o grupo e a sociedade; propicia uma reorganização e recriação de seu sistema simbólico perante o espectador, viabilizando a construção ou reconstrução de uma identidade de fronteira, isto é, permanentemente traduzida.

Pondera-se que as manifestações culturais não equivalem a entidades puras ou fixas, dissociadas do contexto social, político ou econômico onde estão inseridas, pelo contrário, são em sua essência resultado de constantes hibridações, trocas, movimentos e trânsitos. Há uma fronteira muito tênue, e em alguns casos, transponível, entre o que se postula autenticidade e artificialidade das produções culturais de uma sociedade.

Isso significa considerar que as performances culturais, cotidianas ou turísticas, são condutas permanentemente restauradas, reproduzidas, no movimento de vir a ser constantes que comporta significados plurais. Segundo Schechner (1985, p. 206), “a representação significa: nunca pela primeira vez. Isso significa: da segunda até n vezes". Nesse sentido, as noções de aura e de autenticidade das formas culturais são entendidas como processo, sendo negociável entre os atores sociais, numa releitura ou reinterpretação das culturas e das identidades que ocorre nas diversas esferas da experiência cotidiana:

Para a teoria da performance, a idéia de autenticidade está fincada no aqui e agora de cada performance realizada, em condições sociais, econômicas e históricas concretas, conforme a intencionalidade de cada realização. Nesse sentido, pode-se afirmar que o autêntico, desse ponto de vista, é aquilo que é real e que se concretiza e materializa num dado momento (VIANNA e TEIXEIRA, 2008, p. 125). 
As práticas culturais são revisitadas, reforçadas e condicionadas a partir de códigos e símbolos anteriormente construídos e retransmitidos entre gerações sucessivas. As apresentações performáticas dos grupos culturais constituem, portanto, remodelações das identidades diante de outros contextos e espaços sociais, incorporando no presente novas significações.

As performances cotidianas, rituais ou artísticas, misturam-se, sofrendo acréscimos a partir de elementos de sofisticação, visuais ou coreográficos, que enriquecem o jogo cênico e elevam o nível de desempenho dos atores sociais, garantindo, assim, a eficácia da representação teatral.

Vistas sob o prisma da teoria da performance, as apresentações da cultura para grupos de visitantes podem ser compreendidas como interpretações possíveis da relação entre texto e contexto, numa releitura contemporânea. As performances turísticas revelam articulações de agentes internos e externos, os quais evidenciam as relações entre centralidade e marginalidade, inclusão e exclusão, ou seja, movimentos "de passagem e significados que são posicionais e relacionais, sempre em deslize ao longo de um espectro sem começo nem fim" (HALL, 2003, p. 33).

Insurgem, portanto, como instâncias de redefinição dos símbolos que codificam as relações sociais entre brincantes e os espectadores em condições cotidianas e extracotidianas. Estas duas dimensões não se tornam mutuamente excludentes; estabelecendo trocas entre si, enriquecem o jogo das identidades locais, sendo os meios de comunicação, as novas tecnologias e o turismo, vetores do hibridismo cultural.

A forma com que os grupos locais reconhecem a dinâmica intercultural e desenvolvem estratégias de visibilidade, correspondem aos diferentes modos de expressividade popular, reconstrução da memória social e, consequentemente, de reposição ou de revigoramento das identidades:

As rodas finais das performances, quando todos se dão as mãos para cantar e dançar, representam o desejo de preservação do espírito da festa popular. De fato, as apresentações culminam invariavelmente num momento musical animado que contagia a platéia e a faz cantar e dançar. Mesmo os espetáculos que se desenrolam num palco terminam assim, reunindo quem tinha sido separado - os artistas que representavam e os "espectadores" diante deles. Instala-se ali uma comunitas fugaz dos cultores das tradições (TRAVASSOS, 2004, p. 110, grifo da autora). 
O resultado desses entrelaçamentos enriquece os conteúdos culturais das celebrações de caráter popular e/ou erudito, produzindo ramificações que se apresentam de forma mais ou menos compatíveis em relação ao modelo tido como primário, ideal ou autêntico da cultura produzida e reinterpretada de geração a geração. Utilizando-se o conceito de comportamento restaurado proposto por Schechner (2003), apreende-se o caráter dinâmico das expressões populares; enquanto atividade cultural dinâmica, as festas pressupõem reelaborações criativas ao longo do tempo, embora estas tendam a se apresentar como práticas semelhantes àquelas verificadas em determinado momento ou contexto histórico.

As relações e trocas entre os atores sociais nas festas propiciam assim, situações em que as identidades se renovam, incorporam novos elementos e se tornam híbridas, transformando as manifestações populares numa experiência coletiva que contribui para o entendimento das posições que os grupos sociais ocupam num determinado mundo social.

O turismo, enquanto momento extraordinário, de suspensão ou ruptura do cotidiano, agrega novos valores e significados à dinâmica das festas populares, implicando processos de adaptação e incorporação, ou seja, de deslocamento de fronteiras, complexificando os mecanismos de representação identitária.

Os lugares materiais e simbólicos onde se desenrolam o intercâmbio cultural configuram-se como territorialidades abertas às constantes influências, sejam elas de ordem interna ou externa, as quais promovem fluxos de relações sociais e comerciais e circulação de bens simbólicos. Estes contribuem decisivamente para a reposição de uma memória e identidade em constante processo de transformação.

Ao apresentarem as formas festivas num determinado texto ou contexto, os brincantes comunicam entre si e perante o público espectador, elementos de uma cultura plural. Apresentadas como performance, legitimação de diversas memórias e identidades, traduzem nos tempos de festa, turismo, lazer e devoção, dinâmicas e significativas ramificações. 


\section{CONSIDERAÇÕES FINAIS}

As comemorações populares como símbolos das vivências dos grupos sociais apresentam-se sob vários matizes, produzindo sentidos e significados ao patrimônio cultural transmitido de geração a geração. Adentrando ao panorama de intercâmbio que ultrapassa as demarcações físicas onde se evidenciam tais manifestações, intensificamse os laços de hibridismo entre as culturas locais e globais.

Nesse sentido, o turismo torna-se fator ativador de processos de hibridação cultural, propiciando a reconfiguração dos patrimônios locais, regionais, e nacionais, com elementos da cultura global. Trata-se de um processo dinâmico balizado em mecanismos sucessivos de construção e reconstrução identitárias, nos quais os atores sociais se apropriam, selecionam e reelaboram determinados atributos culturais, de acordo com os diferentes contextos ou momentos históricos, do qual a atividade turística constitui-se parte integrante.

Nesse sentido, as asseverações encetadas pelos estudos antropológicos vêm reorientando as análises acerca dos eventos e das produções de caráter turístico para além dos processos de aculturação, evidenciando os mecanismos de reflexividade, tradução cultural e o caráter interpretativo das performances turísticas.

Inserido numa perspectiva analítica propiciada pelos estudos da performance, as transformações contínuas na forma de apresentação das manifestações populares em virtude da atividade turística acompanham a dinâmica social dos sistemas simbólicos por meio da capacidade de ressignificação, interpretação e reflexividade dos atores sociais. Nelas ocorrem constantes mecanismos de articulação, seleção e apropriação de elementos decorrentes do maior contato entre os diferentes grupos culturais.

Nas performances turísticas ocorre uma reordenação da realidade material e simbólica dos legitimadores das manifestações populares, dos valores sagrados e profanos inerentes aos sistemas simbólicos, ao mesmo tempo em que o recriam, articulando diferentes experiências: sagrada/profana, individual/grupal, cotidiana/profissional. Em todas essas situações, os laços de pertença ao universo ritualístico das manifestações populares são reforçados. 


\section{REFERÊNCIAS}

AGIER, M. Exu e o Diabo em ruas de carnaval: as identidades negras em questão (Brasil, Colômbia). In: BIRMAN, P. (Org.). Religião e espaço público. São Paulo: Attar Editorial, 2003.

BHABHA, H. K. O local da cultura. Belo Horizonte: Ed. UFMG, 1998.

BRUNER, E. Culture on tour: ethnographies of travel. Chicago University Press, 2004.

BURNS, P. M. Turismo e antropologia: uma introdução. São Paulo: Chronos, 2002.

CANCLINI, N. G. Culturas híbridas. Estratégias para entrar e sair da modernidade. São Paulo: Edusp, 2000.

CARDOSO DE OLIVEIRA, Roberto. Caminhos da Identidade: Ensaios de Etnicidade e multiculturalismo. São Paulo: Editora UNESP; Brasília: Paralelo 15, 2006.

CARVALHO, J. J. O lugar da cultura tradicional na sociedade moderna In:

(Org.). Seminário Folclore e Cultura Popular: as várias faces de um debate. Centro Nacional de Folclore e Cultura Popular/FUNARTE, Rio de Janeiro, 2000, p. 23-38.

CHUVA, M. Patrimônio imaterial: práticas culturais na construção de identidades de grupos. In: SECRETARIA DE ESTADO DA EDUCAÇÃO DE MINAS GERAIS. Reflexões e contribuições para a educação patrimonial. Grupo Gestor (Org.) - Belo Horizonte SEE/MG, 2002.

DAWSEY, J. C. O teatro dos "bóias-frias": repensando a antropologia da performance. In: Horizontes Antropológicos, Porto Alegre, ano 11, n. 24, p. 15-34, jul./dez. 2005.

FOUSS, K. W.; HILL, R. T. G. Spectacular imaginings: Performing Community in Guatemala. In: GRANT H.; STODDARD, E. W. (Orgs.). Global Multiculturalism Cornwell. Maryland: Rowman \& Littlefield, 2000, p. 93-120.

GIDDENS, A. As conseqüiências da modernidade. São Paulo: UNESP, 2002.

GOFFMANN, E. A representação do eu na vida cotidiana. Petrópolis: Vozes, 1995.

GRÜNEWALD, R. de A. Indigenismo, turismo e mobilização étnica. In: GRABURN, N.; BARRRETTO, M.; STEIL, C. A.; GRÜNEWALD, R. de A.; SANTOS, J. R. dos (Orgs.). Turismo e Antropologia: novas abordagens. São Paulo: Papirus, 2009, p. 97118.

GUARINELlO, N. L. Festa Trabalho e Cotidiano. In: JANCSÓ, I; KHANTOR, Í. Festa: Cultura e Sociabilidade na América, v. II. São Paulo: HUCITEC: Editora da Universidade de São Paulo, FAPESP: Imprensa Oficial, 2001. 
GUSS, D. The Festive State - race, ethnicity, and nationalism as cultural performance. Berkeley and Los Angeles, University of California Press, 2000.

HALL, S. Da diáspora: identidades e mediações culturais. Belo Horizonte: Editora UFMG, 2003.

LANGDON, E. J. Performance e sua diversidade como paradigma analítico: a contribuição da abordagem de Bauman e Briggs. In: BASTOS, R. J. de M. (Ed.). Revista Antropologia em Primeira Mão, Florianópolis: Universidade Federal de Santa Catarina, 2007, p. 5-26.

LIGIÉRO, Z. Performances Procissionais Afro-Brasileiras. In: O Percevejo, Revista de Teatro, crítica e estética. Estudos da Performance. (11)12. Programa de Pós-Graduação em Teatro da UNIRIO: Departamento de Teoria do Teatro, 2003, p. 84-98.

. As performances de Zé Pilintra: ritual e jogo. In: LOPES, A. H. (Org.). Religião e Performance ou as performances das religiões brasileiras. Rio de Janeiro; Edições Casa Rui Barbosa, 2007. p. 119-127.

LUCAS, S. M. Turismo cultural no vale do Paraíba. Uma exposição histórica. In: II CONGRESSO BRASILEIRO DE TURISMO RURAL, 2000. Anais... Piracicaba, 2000.

MAUSS, M. Sociologia e antropologia. São Paulo: v. 1, E. P. U./Edusp, 1974.

SANTANA, A. Antropologia do turismo: analogias, encontros e relações. Tradução de Eleonora Frenkel Barretto. São Paulo: Aleph, 2009.

SCHECHNER, R. Between Theater and Anthropology. Philadelphia: The University of Pennsylvania Press, 1985.

O que é performance. In: O Percevejo, Revista de Teatro, crítica e estética. Estudos da Performance. (11)12 Rio de Janeiro, Departamento de Teoria do Teatro: Programa de Pós-Graduação em Teatro da UNIRIO: 2003, p. 25-50.

SINGER, M. When a Great Tradition Modernizes. Chicago, University of Chicago Press, 1972.

TEJERINA, B. Multiculturalismo, movilización social y procesos de construcción de la identidad en el contexto de la globalización, 2003. Disponível em: <http://www.ces.fe.uc.pt/publicacoes/oficina/187/187.pdf>. Acesso em: 03/05/2011.

TRAVASSOS, E. Recriações contemporâneas dos folguedos tradicionais. In: TEIXEIRA, J. G. L; GARCIA, M. V. C.; GUSMÃO, R. (Orgs.). Patrimônio imaterial, performance cultural e (re)tradicionalização. Brasília: UNB, 2004, p.110-16.

TURNER, V. O processo ritual. Petrópolis: Vozes, 1974. 
Images of anti-temporality: essay in the anthropology of experience. In: The Harvard Theological Review, 75(2): 1982, p. 243-265.

Dramas, campos e metáforas. Ação simbólica na sociedade moderna. Niterói: Editora da UFF, 2008.

VAN GENNEP, A. Os ritos de passagem. Petrópolis: Vozes, 1978.

VIANNA, L. C. R.; TEIXEIRA, J. G. L. C. Patrimônio imaterial, performance e identidade" In: Concinnitas, Revista do Instituto de Artes do Estado do Rio de Janeiro ano 9, 1(12): 121-129, 2008. Disponível em: 〈http://www.concinnitas.uerj.br/〉. Acesso em: $20 / 11 / 2010$.

URRY, J. O olhar do turista: lazer e viagens nas sociedades contemporâneas. São Paulo: EDUSC, 1996.

Recebido em: 26-05-2011.

Aprovado em: 26-06-2011. 